\title{
Comparing intraoperative transesophageal and postoperative transthoracic echocardiography findings in mitral valve surgery: what changes?
}

Patrícia Marques Alves ( $\nabla$ pat.marques.alves@gmail.com )

Centro Hospitalar e Universitário de Coimbra https://orcid.org/0000-0002-2639-4058

Carlos Branco

Centro Hospitalar e Universitario de Coimbra EPE

Ana Vera Marinho

Centro Hospitalar e Universitario de Coimbra EPE

Ana Rita Rita Ramalho

Centro Hospitalar e Universitario de Coimbra EPE

Maria João João Maldonado

Centro Hospitalar e Universitario de Coimbra EPE

\section{Gonçalo Coutinho}

Centro Hospitalar e Universitario de Coimbra EPE

David Prieto

Centro Hospitalar e Universitario de Coimbra EPE

Lino Gonçalves

Centro Hospitalar e Universitario de Coimbra EPE

Pedro Antunes

Centro Hospitalar e Universitario de Coimbra EPE

Research article

Keywords: mitral valve surgery, intraoperative transesophageal echocardiography, mean pressure gradient

Posted Date: October 24th, 2019

DOI: https://doi.org/10.21203/rs.2.16406/v1

License: (1) (1) This work is licensed under a Creative Commons Attribution 4.0 International License. Read Full License 


\section{Abstract}

OBJECTIVES Intraoperative transesophageal echocardiography (iTEE) has an important role in diagnosing the results of mitral valve (MV) replacement and repair. However, intraoperative Doppler features may be dissimilar from those measured at the postoperative follow-up period due to hemodynamic variations. There are no studies regarding MV surgery and comparisons between iTTE and postoperative transthoracic echocardiography (post-TTE). We aimed to evaluate the Doppler flow profiles observed in iTEE after MV replacement and repair and compare them with those observed in post-TTE.

METHODS We conducted an observational study of 76 patients who underwent MV surgery (replacement or repair) over a 10-month period. iTEE was performed with Doppler evaluation (mean pressure gradient [MPG] and functional area). Patients were re-evaluated with TTE 72 hours after surgery (post-TTE). iTEE and post-TTE Doppler values were then compared and correlated.

RESULTS The patients' mean age was $59 \pm 18$ years and $55 \%$ were women. The prevalence of severe mitral regurgitation and severe mitral stenosis was $77.6 \%$ and $22.4 \%$, respectively. MV repair was performed in $71 \%$ of cases. iTEE Doppler parameters correlated with post-TTE parameters, with minimal differences, specially in the MV repair group. The postoperative MPG was $+0.4 \pm 1 \mathrm{mmHg}$ higher in the $M V$ repair group and $+1.0 \pm 1.8 \mathrm{mmHg}$ in the $\mathrm{MV}$ replacement group. There was global improvement in terms of systolic pulmonary artery pressure, although left ventricular ejection fractions were slightly reduced during the postoperative evaluation.

CONCLUSIONS Our study demonstrates the usefulness of iTEE and its importance in establishing possible reference values for postoperative follow-ups.

\section{Introduction}

Mitral valve (MV) disease, particularly mitral regurgitation (MR), is a growing global health problem that affects millions worldwide ${ }^{1,2}$. Fortunately, mitral repair is potentially curative and often provides excellent long-term event-free survival ${ }^{3}$. MV repair is indicated for patients with symptomatic severe regurgitation and asymptomatic patients with evidence of left ventricular dysfunction. Repair may also be indicated for asymptomatic patients with severe regurgitation and normal ventricular function ${ }^{3}$. Although $\mathrm{MV}$ repair is superior to replacement, repair is currently accomplished in about $60 \%$ of cases (no higher than $85 \%$ cases in the most optimally selected subgroups) ${ }^{3,4}$.

Transesophageal echocardiography (TEE) is indispensable for the optimal management of mitral disease. MV repair is currently facilitated by the accurate assessment of MV anatomy and MR mechanisms through comprehensive TEE ${ }^{5,6}$. Additionally, intraoperative TEE (iTEE) has become a routine monitoring technique for heart-valve surgery evaluation, and has been reported to improve outcomes after the termination of cardiopulmonary bypass (CPB) ${ }^{7,8,9}$. 
Notably, the intraoperative Doppler features of prosthetic valves, especially those pertaining to flowdependent parameters, such as peak velocity and mean pressure gradient (MPG), may be dissimilar to those measured at the postoperative follow-up period. This may be due to changes in hemodynamic status, the management of intraoperative cardiac output via inotropes, changes in preload, CPB-induced myocardial edema, and depressed myocardial contractility 7,8 .

To the best of our knowledge, there are no studies regarding MV surgery and comparisons between intraoperative echocardiographic observations and 72-hour post-surgery echocardiographic observations. Consequently, the aim of our study was to determine the iTEE characteristics and Doppler flow profiles of MVs after repair and replacement and correlate them with postoperative transthoracic echocardiography (post-TTE) data obtained at 72 hours after surgery.

\section{Methods}

\section{Study population}

We conducted an observational study of 76 patients that underwent MV surgery from December 2017 to October 2018 in the Department of Cardiothoracic Surgery of Centro Hospitalar e Universitário de Coimbra. We included severe MR and mitral stenosis (MS) patients who underwent either MV repair or replacement. Patients with significant coronary disease (stenosis $>50 \%$ ) were excluded. This study was approved by the institutional scientific and bioethical committees of Centro Hospitalar e Universitário de Coimbra and was performed in accordance with the Declaration of Helsinki.

\section{Study procedures}

\section{Preoperative evaluation}

A preoperative TTE (pre-TTE) evaluation was performed to gather data, such as left ventricular ejection fraction (LVEF), left ventricle (LV) diameter, right ventricle (RV) function and diameter, and systolic pulmonary artery pressure (sPAP).

\section{Intraoperative evaluation}

In the operating room, an adult-size TEE probe was inserted into patients after anesthesia induction, and their heart was inspected using an ultrasound system (Vivid ${ }^{\mathrm{TM}} \mathrm{E95}, \mathrm{GE}$ Healthcare). CPB was established and $M V$ repair or $M V$ replacement was performed. Next, inotropic infusions were performed for all patients before CPB weaning. These perfusions were done in accordance with institutional protocols. Then, the TEE examination of repaired MVs or prosthesis was done by an echocardiographer when stable hemodynamic parameters were attained. 


\section{Assessing MV repair}

The iTEE evaluation assessed MV residual regurgitation, which was done through color Doppler imaging. Continuous wave Doppler in either transesophageal four-chamber view or transesophageal long-axis view, wherein the ultrasound beam could be aligned parallel to the MV flow, was assessed to determine MPG and indirectly determine the functional MV area (via the pressure half-time method).

\section{Assessing MV replacement}

Assessment of the stability of the seating of prostheses and the detection of any paravalvular or intravalvular regurgitation were performed via color Doppler imaging. Prostheses were interrogated using continuous wave Doppler in either transesophageal four-chamber view or transesophageal long-axis view, wherein the ultrasound beam could be aligned parallel to the flow. MPG and, indirectly, functional prothesis area (via the pressure half-time method) were determined.

\section{Postoperative evaluation}

Patients were re-evaluated via TTE at 72 hours after surgery. Using an apical 4-, 3- and 2-chamber view, residual MV or paravalvular regurgitation was assessed via color Doppler imaging. Continuous wave Doppler ultrasound was used to directly determine MPG and indirectly (pressure half-time method) determine the functional MV/prothesis area. Additionally, LVEF, LV diameters, RV function and diameter, and SPAP were measured. Analysis of residual MR was also performed by color doppler and grades of valvular regurgitation were defined as per the guidelines issued by the European Society of Cardiology and the European Association for Cardio-Thoracic Surgery ${ }^{14}$. iTEE and post-TTE Doppler values were then compared and correlated.

\section{Statistical analysis}

The normality of continuous variables was assessed via histogram observation and the KolmogorovSmirnov test. Continuous variables were expressed as mean \pm standard deviation, and categorical variables as percentage. Student's t-test or ANOVA was used for group comparisons. Individual variables were assessed for homogeneity of variance using Levene's test. For categorical variables, the chi-square test or Fisher's exact test was used, as appropriate. A paired t-test was performed to compare pre-TTE, post-TTE, and iTEE parameters.

A P value (two-sided) of $<0.05$ indicated statistical significance. Stata software (Stata IC for Windows, version 14, Lakeway Drive, TX, USA) was used for all statistical analyses.

\section{Results}




\section{Study population}

The study population's characteristics are described in Table 1. The patients' mean age was $59 \pm 18$ years and $55 \%$ were female. The prevalence of MR and MS was $77.6 \%$ and $22.4 \%$, respectively. The etiology of MR was rheumatic in $25 \%$ of cases, degenerative in $61 \%$, endocarditis in $5 \%$, and secondary in $8.5 \%$. The etiology of MS was rheumatic in all cases. MV repair was performed in $71 \%$ of cases $(64 \%$ underwent total annuloplasty and $36 \%$ partial posterior annuloplasty). In MV repair surgery, $83 \%$ cases were performed for MR and 17\% for MS. MV replacement occurred in $29 \%$ patients (64\% performed for MR cases and $46 \%$ performed for MS cases). MV replacement occurred in $29 \%$ cases; replacement with mechanical prothesis occurred in $6.6 \%(n=5)$ patients. Patients submitted to MV repair were younger and exhibited less frequent atrial fibrillation and pulmonary hypertension than those submitted to MV replacement.

\section{Preoperative and postoperative global assessment}

LVEF, LV end-diastolic diameter (LVDD), sPAP, right ventricular diameter (RVD), and tricuspid annular plane systolic excursion (TAPSE) assessed in pre-TTE and post-TTE are depicted in Table 2. Overall, there was a slight reduction in biventricular function from pre-surgery to post-surgery, as determined by LVEF and TAPSE. Ventricular dimensions did not significantly vary between MS patients. Regarding the type of surgery, there was no significant difference in RVD values after MV repair $(p=0.221)$, and LVDDs did not significantly vary after MV replacement $(p=0.182)$.

\section{MPG and estimated functional areas}

MPG values and estimated functional mitral areas assessed by iTEE and post-TTE are described in Table 3 and Figure 1.

In patients who underwent MV repair, there were no significant differences between iTEE and post-TTE in terms of derived MPG values $(p=0.084)$ and estimated functional mitral areas $(p=0.665)$ (postoperative MPG was $+0.4 \pm 1 \mathrm{mmHg}$ higher than intraoperative MPG). In regard to the type of MV repair, there was no significant differences in iTEE MPG values between patients who underwent total mitral annuloplasty $(2.9 \pm 1.4 \mathrm{mmHg})$ and those that underwent partial annuloplasty $(2.6 \pm 1.4 \mathrm{mmHg})(p=0.448)$. No significant differences were observed in the post-TTE MPG values between such patients as well (total mitral annuloplasty, $3.1 \pm 1.3 \mathrm{mmHg}$; partial annuloplasty, $3.4 \pm 1.6 \mathrm{mmHg} ; \mathrm{p}=0.494)$. However, in partial annuloplasty cases, the post-TTE MPG values were significantly higher than the iTEE MPG values $(2.6 \pm$ 1.5 vs $3.4 \pm 1.6 \mathrm{mmHg}, p=0.025$ ).

In patients that underwent MV replacement, the post-TTE MPG values were significantly higher than the ITEE MPG values (postoperative MPG was $+1.0 \pm 1.8 \mathrm{mmHg}$ higher than intraoperative MPG, $p=0.016$ ), but there were no significant differences between the iTEE and post-TTE estimated functional prosthesis areas $(p=0.653)$. 
Moreover, there was a higher numerical difference between iTEE and post-TTE MPG values for mechanical valves ( $n=5 ; 3.5 \pm 1.2$ to $5.2 \pm 1.6 \mathrm{mmHg}$; difference of $1.65 \pm 2.4 \mathrm{mmHg}$ ) than for biological valves $(\mathrm{n}=17 ; 3.1 \pm 1.1$ to $3.9 \pm 1.5 \mathrm{mmHg}$; difference of $0.8 \pm 1.7 \mathrm{mmHg})$.

In regard to post-surgery MR grades, the majority of cases were classified as mild during iTEE, and there were no significant differences in MR grade after the post-TTE evaluation (Table 3)..

\section{Discussion}

Our study results revealed a correlation between iTEE Doppler parameters and postoperative TTE parameters with minimal differences, particularly in patients submitted to MV repair. There was also global improvement in terms of SPAP, although LVEF and TAPSE were slightly reduced during the postoperative evaluation.

iTEE has become an essential assessment tool in heart-valve surgeries ${ }^{10-12}$, and it is particularly important in evaluating the anatomy of the $M V^{5,6,13}$, namely in $M V$ repair ${ }^{5,6}$. MV repair is preferred over $M V$ replacement for treating degenerative MV disease ${ }^{14}$. In our study, about $70 \%$ of patients underwent $M V$ repair, which is a relevant proportion when compared with other reports ${ }^{3,4}$. In patients who underwent MV repair, the mean iTEE MPG value was $2.8 \pm 1.5 \mathrm{mmHg}$ and the mean post-TTE MPG value was $3.1 \pm$ $1.4 \mathrm{mmHg}$. These results are highly similar to those reported in a previous study, in which the mean iTEE MPG value was $3.1 \pm 1.4 \mathrm{mmHg}$ and the mean post-TTE MPG value was $3.5 \pm 1.6 \mathrm{~mm} \mathrm{Hg}^{15}$. Additionally, in regard to the type of MV repair, there were no significant differences in the iTEE MPG and post-TTE MPG values between patients who underwent either total or partial annuloplasty. Previous studies have reported that, compared to partial rings, complete rings may be associated with higher MV gradients ${ }^{16}$. Another report also supports the concept that restrictive annuloplasty results in small valve gradients ${ }^{15}$. However, in our cohort, only the iTEE MPG values were higher in the total annuloplasty group, and only the post-TTE MPG values were higher in the partial annuloplasty group. Hence, with these inconclusive data, we cannot confirm whether the hemodynamic effects of MV repair in our study are consistent with what has been previously reported.

TEE evaluation in the post-CPB period has important effects in the outcomes of valve replacement surgeries $^{9,17}$. Even so, there are few reports describing iTEE Doppler characteristics of repaired MVs and prosthetic MVs. This has led us to evaluate iTEE Doppler features and correlate them with post-TTE data. Post-CBP Doppler derided velocities and gradients depend on several hemodynamic effects, like inotropes, surgical bleeding and blood transfusion ${ }^{9,18}$. Post-CBP changes in loading conditions lead to changes in stroke volumes, which modify Doppler velocities and pressure gradients ${ }^{9,17,18}$. Therefore, the ability of these flow-dependent parameters to accurately and reliably represent repaired valve/prosthetic valve function is questionable.

The most important limitation in our study is that the evaluated pressure gradient across the MV is highly dependent on hemodynamics, and it cannot solely be relied on for the assessment of valve stenosis. 
Moreover, the gold standard for detecting MS is 3D derived valve area, which is highly feasible and has added value in all other aspects of postoperatively assessing MV repair/replacement ${ }^{19,20}$. Nonetheless, even not using 3D-echocardiography, we have shown that calculating the valve area by the simplest method (using the pressure half-time) intraoperatively correlates with post-TTE measurements.

In our study, MPGs and functional areas attained during the intraoperative period and third postoperative day globally were not significantly different, particularly in the MV repair group. This suggests that when Doppler assessment is performed after optimizing loading conditions and hemodynamics during the intraoperative period, the function of prostheses may be accurately reproduced in the postoperative period, which was when prostheses were evaluated in stable loading conditions. Therefore, intraoperative Doppler values could be regarded as reference values for postoperative ultrasonic follow-up studies, especially after MV repair.

A minor limitation in this study is the fact that subjects were selected from a single tertiary referral center. A multicenter study involving a diverse ethnic population with different heights, weights, and body surface areas would be superior in generalizing echocardiographic characteristics. Moreover, although we obtained satisfactory conclusions from 76 patients, the inclusion of a larger number of subjects would offer more accurate and reliable results.

\section{Conclusion}

In our study, iTEE Doppler parameters correlated with postoperative TTE parameters with minimal differences, especially in patients who underwent MV repair. There was global improvement in terms of SPAP, although LVEF was slightly reduced during the postoperative evaluation. Our study demonstrates the usefulness of iTEE and its importance in establishing possible reference values for postoperative follow-ups to increase the chance of favorable outcomes.

\section{Abbreviations}

CPB-cardiopulmonary bypass

iTEE-intraoperative transesophageal echocardiography

LV-left ventricle

LVDD-left ventricular diastolic diameter

LVEF-left ventricular ejection fraction

MPG-mean pressure gradient

MR-mitral regurgitation 
MS-mitral stenosis

$\mathrm{MV}-$ mitral valve

NYHA-New York Heart Association

Post-TTE-postoperative transthoracic echocardiography

RV-right ventricle

RVD-right ventricular diameter

sPAP-systolic pulmonary artery pressure

SD-standard deviation

TAPSE-tricuspid annular plane systolic excursion

TEE-Transesophageal echocardiography

TTE-Transthoracic echocardiography

\section{Declarations}

\section{Ethics approval and consent to participate}

Since it was an observational analysis of a previously anonymized database, informed consent was not obtained from patients. The study was approved by the ethics committee of Centro Hospitalar e Universitário de Coimbra.

\section{Consent for publication}

Not applicable.

\section{Availability of data and materials}

The datasets used and/or analyzed during the current study are available from the corresponding author on reasonable request.

\section{Competing interests}

The authors declare that they have no competing interests in this section. 


\section{Funding}

Not applicable.

\section{Authors' contributions}

PMA, conception and design, analysis and interpretation of data, manuscript writing. CB, AVM, acquisition, analysis and interpretation of data. ARR, MJM conception and design, analysis and interpretation of data, revising the manuscript critically for important intellectual content. GC, DP, PA attending physicians, analysis and interpretation of data, revising the manuscript critically for important intellectual content. LG, PA, interpretation of data, revising the manuscript critically for important intellectual content. All authors read and approved the final manuscript

\section{Acknowledgements}

Not applicable.

\section{References}

1. Enriquez-sarano M, Akins CW, Vahanian A. Mitral regurgitation. Lancet. 2009;373(9672):1382-1394. doi:10.1016/S0140-6736(09)60692-9

2. Do W, Stand WE. Rheumatic fever and rheumatic heart disease Report by the Director - General. 2018;2016(March):1-6.

3. Shuhaiber J, Anderson RJ. Meta-analysis of clinical outcomes following surgical mitral valve repair or replacement. 2007;31. doi:10.1016/j.ejcts.2006.11.014

4. Gammie JS, Zhao Y, Peterson ED, Brien SMO, Rankin JS, Griffith BP. Less-Invasive Mitral Valve Operations: Trends and Outcomes From The Society of Thoracic Surgeons Adult Cardiac Surgery Database. ATS. 2010;90(5):1401-1410.e1. doi:10.1016/j.athoracsur.2010.05.055

5. Grewal J, Mankad S, Freeman WK, Click R L, Suri RM, Abel MD, et al. Real-Time Three-Dimensional Transesophageal Echocardiography in the Intraoperative Assessment of Mitral Valve Disease. YMJE. 22(1):34-41. doi:10.1016/j.echo.2008.11.008

6. Drake DH, Zimmerman KG, Ae R, Hepner AM, Nichols CD. Echo-Guided Mitral Repair. 2015. doi:10.1161/CIRCIMAGING.112.000458

7. Nowrangi SK, Connolly HM, Freeman WK. Impact of Intraoperative Transesophageal Echocardiography Among Patients Undergoing Aortic Valve Replacement for Aortic Stenosis. 2001;55905:863-866. doi:10.1067/mje.2001.113368

8. Eltzschig HK, Rosenberger P, Löffler M, Fox JA, Aranki SF, Shernan SK. Impact of Intraoperative Transesophageal Echocardiography on Surgical Decisions in 12, 566. 2008. doi:10.1016/j.athoracsur.2007.11.015 
9. Babu S, Sreedhar R, Gadhinglajkar S V, Dash K, Sukesan S, Shriram L, et al. Intraoperative Transesophageal and Postoperative Transthoracic Echocardiographic Evaluation of a Mechanical Heart Valve Prosthesis Implanted at Aortic Position. J Cardiothorac Vasc Anesth. 2017:1-8. doi:10.1053/j.jvca.2017.09.001

10. Emperador F, Fita G, Arguís MJ, Gómez I, Tresandi D, Matute P et al. Revista Española de Anestesiología y Reanimación Importancia de la ecocardiografía transesofágica intraoperatoria en la decisión quirúrgica en cirugía cardiaca. Rev Esp Anestesiol Reanim. 2014. doi:10.1016/j.redar.2014.03.007

11. Siau C, Ti LK. Author ' s Accepted Manuscript. J Cardiothorac Vasc Anesth. 2017. doi:10.1053/j.jvca.2017.05.027

12. Flachskampf FA, Badano L, Daniel WG, Feneck RO, Fox KF, Fraser AG, et al. Recommendations for transoesophageal echocardiography: update 2010. 2010:557-576. doi:10.1093/ejechocard/jeq057

13. Alreshidan M, Herron RD, Wei LM, Cook CC, Salman M, Roberts HG, et al. Contemporary Surgical Techniques for Mitral Valve Repair: A Pathoanatomic Appraisal. 2018.

doi:10.1177/1089253218815465

14. Baumgartner H, Falk V, Bax JJ, De Bonis M, Hamm C, Holm PJ et al. 2017 ESC/EACTS Guidelines for the management of valvular heart disease. Eur Heart J. 2017;38(36):2739-2786. doi:10.1093/eurheartj/ehx391

15. Murashita T, Greason KL, Suri RM, Daly RC, Joyce LD, Stulak JM, et al. Mitral valve gradient after valve repair of degenerative regurgitation with restrictive annuloplasty. J Thorac Cardiovasc Surg. 2013:1-5. doi:10.1016/j.jtcvs.2015.08.078

16. Mesana TG, Lam B, Chan V. Clinical evaluation of functional mitral stenosis after mitral valve repair for degenerative disease: Potential affect on surgical strategy. J Thorac Cardiovasc Surg. 2013;146(6):1418-1425. doi:10.1016/j.jtcvs.2013.08.011

17. Shapira Y, Weisenberg DE, Vaturi M, Sharoni E, Raanani E. The Impact of Intraoperative Transesophageal Echocardiography in Infective Endocarditis. 2007;9(April):299-302.

18. Parnell A, Swanevelder J. High transvalvular pressure gradients on intraoperative transesophageal echocardiography after aortic valve replacement: what does it mean? Intensive Care and Cardiovascular Anesthesia

19. Shiota T. Role of modern 3D echocardiography in valvular heart disease. Korean J Intern Med. 2014;29(6):685-702. doi:10.3904/kjim.2014.29.6.685

20. Poelaert JI, Bouchez S. Perioperative echocardiographic assessment of mitral valve regurgitation: A comprehensive review. Eur J Cardio-thoracic Surg. 2016;50(5):801-812. doi:10.1093/ejcts/ezw196

\section{Tables}

Table 1. Study population characteristics 


\begin{tabular}{|c|c|c|c|c|c|c|}
\hline & \multicolumn{3}{|c|}{ MV disease } & \multicolumn{3}{|c|}{ MV surgery } \\
\hline Patient Characteristics & $\begin{array}{c}\text { MR } \\
(\mathrm{n}=59)\end{array}$ & $\begin{array}{c}\text { MS } \\
(n=17)\end{array}$ & $\begin{array}{c}P \\
\text { value }\end{array}$ & $\begin{array}{l}\text { MV } \\
\text { repair } \\
(\mathrm{n}=54)\end{array}$ & $\begin{array}{c}\text { MV } \\
\text { replacement } \\
(\mathrm{n}=22)\end{array}$ & $\begin{array}{c}P \\
\text { value }\end{array}$ \\
\hline Female (\%) & $53 \%$ & $79 \%$ & 0.076 & 50 & 70 & 0.148 \\
\hline Age (mean $\pm \mathrm{SD}$, years) & $\begin{array}{c}58 \pm \\
19\end{array}$ & $\begin{array}{c}63 \pm \\
14\end{array}$ & 0.336 & $\begin{array}{c}56 \pm \\
19 \\
\end{array}$ & $66 \pm 12$ & 0.032 \\
\hline MR (\%) & & & & 87 & 64 & 0.213 \\
\hline Rheumatic MR (\%) & $N / A$ & $N / A$ & $N / A$ & 30.2 & 55 & 0.124 \\
\hline Degenerative MR (\%) & $N / A$ & $N / A$ & $\overline{N / A}$ & 52.8 & 40 & 0.542 \\
\hline Secondary MR (\%) & $N / A$ & $N / A$ & $N / A$ & 13.2 & 0 & $N / A$ \\
\hline Endocarditis MR (\%) & $N / A$ & $N / A$ & $N / A$ & 3.8 & 5 & 0.109 \\
\hline MS (\%) & & & & 13 & 46 & $\begin{array}{l}< \\
0.001\end{array}$ \\
\hline NYHA class I (\%) & 0.3 & 0 & & 4 & 0 & \\
\hline NYHA class II (\%) & 44 & 29 & 0.082 & 48 & 32 & 0.315 \\
\hline NYHA class III (\%) & 49 & 71 & 0.074 & 44 & 68 & 0.153 \\
\hline NYHA class IV (\%) & 0.3 & 0 & $N / A$ & 4 & 0 & $N / A$ \\
\hline Atrial fibrillation (\%) & 51 & 64 & 0.364 & 39 & 86 & $\begin{array}{c}< \\
0.001\end{array}$ \\
\hline $\begin{array}{l}\text { Moderate to severe tricuspid } \\
\text { regurgitation (\%) }\end{array}$ & 36 & 50 & 0.319 & 35 & 45 & 0.403 \\
\hline LVEF (mean \pm SD, \%) & $57 \pm 9$ & $58 \pm 6$ & 0.583 & $58 \pm 8$ & $56 \pm 9$ & 0.447 \\
\hline LVDD (mean $\pm \mathrm{SD}, \mathrm{mm})$ & $56 \pm 7$ & $49 \pm 7$ & 0.005 & $55 \pm 8$ & $54 \pm 7$ & 0.580 \\
\hline sPAP (mean \pm SD, mmHg) & $\begin{array}{c}42 \pm \\
17 \\
\end{array}$ & $\begin{array}{c}47 \pm \\
18\end{array}$ & 0.615 & $\begin{array}{c}41 \pm \\
16\end{array}$ & $50 \pm 4$ & 0.034 \\
\hline RVD (mean \pm SD, mm) & $35 \pm 7$ & $34 \pm 7$ & 0.475 & $39 \pm 7$ & $41 \pm 9$ & 0.374 \\
\hline TAPSE (mean \pm SD, mm) & $18 \pm 2$ & $18 \pm 2$ & 0.974 & $19 \pm 2$ & $19 \pm 4$ & 0.566 \\
\hline $\begin{array}{l}\text { LVDD, left ventricular diastolic diame } \\
\text { MS, mitral stenosis; MV, mitral valve } \\
\text { sPAP, systolic pulmonary artery pres } \\
\text { excursion }\end{array}$ & VEF, le & & & raction; & & $\begin{array}{l}\text { tion; } \\
\text { neter; } \\
\text { tolic }\end{array}$ \\
\hline
\end{tabular}

Table 2. Echocardiographic features assessed during the preoperative and postoperative periods 


\begin{tabular}{|c|c|c|c|c|c|c|}
\hline & \multicolumn{3}{|c|}{ MR } & \multicolumn{3}{|c|}{ MS } \\
\hline & $\begin{array}{l}\text { pre- } \\
\text { TTE }\end{array}$ & $\begin{array}{l}\text { post- } \\
\text { TTE }\end{array}$ & $P$ value & pre-TTE & post-TTE & $P$ value \\
\hline LVEF (mean \pm SD, \%) & $57 \pm 9$ & $52 \pm 10$ & $\begin{array}{c}< \\
0.001\end{array}$ & $58 \pm 6$ & $56 \pm 7$ & $<0.001$ \\
\hline LVDD (mean $\pm \mathrm{SD}, \mathrm{mm})$ & $56 \pm 7$ & $53 \pm 7$ & $\begin{array}{c}< \\
0.001\end{array}$ & $49 \pm 7$ & $49 \pm 8$ & 0.943 \\
\hline $\begin{array}{l}\text { sPAP (mean } \pm \text { SD, } \\
\text { mmHg) }\end{array}$ & $42 \pm 17$ & $33 \pm 9$ & $\begin{array}{c}<< \\
0.001\end{array}$ & $47 \pm 18$ & $35 \pm 6$ & $<0.001$ \\
\hline RVD (mean \pm SD, mm) & $35 \pm 7$ & $32 \pm 6$ & 0.023 & $34 \pm 7$ & $32 \pm 6$ & 0.159 \\
\hline \multirow[t]{3}{*}{ TAPSE (mean \pm SD, mm) } & $18 \pm 2$ & $14 \pm 3$ & $\begin{array}{c}< \\
0.001 \\
\end{array}$ & $18 \pm 2$ & $14 \pm 3$ & $<0.001$ \\
\hline & \multicolumn{3}{|c|}{ MV repair } & \multicolumn{3}{|c|}{ MV replacement } \\
\hline & $\begin{array}{l}\text { pre- } \\
\text { TTE }\end{array}$ & $\begin{array}{l}\text { post- } \\
\text { TTE }\end{array}$ & $P$ value & $\begin{array}{l}\text { pre- } \\
\text { TEE }\end{array}$ & post-TTE & $P$ value \\
\hline LVEF (mean \pm SD, \%) & $58 \pm 8$ & $53 \pm 10$ & $\begin{array}{c}< \\
0.001\end{array}$ & $56 \pm 9$ & $51 \pm 9$ & $<0.001$ \\
\hline LVDD (mean $\pm \mathrm{SD}, \mathrm{mm})$ & $55 \pm 8$ & $52 \pm 7$ & $\begin{array}{c}< \\
0.001\end{array}$ & $54 \pm 7$ & $53 \pm 9$ & 0.182 \\
\hline $\begin{array}{l}\text { sPAP (mean } \pm \text { SD, } \\
\text { mmHg) }\end{array}$ & $41 \pm 16$ & $33 \pm 9$ & $\begin{array}{c}<< \\
0.001 \\
\end{array}$ & $50 \pm 4$ & $37 \pm 5$ & 0.002 \\
\hline RVD (mean $\pm \mathrm{SD}, \mathrm{mm})$ & $39 \pm 7$ & $38 \pm 7$ & 0.211 & $41 \pm 9$ & $37 \pm 5$ & 0.005 \\
\hline TAPSE (mean \pm SD, mm) & $19 \pm 2$ & $14 \pm 3$ & $\begin{array}{c}< \\
0.001 \\
\end{array}$ & $19 \pm 4$ & $14 \pm 2$ & $<0.001$ \\
\hline \multicolumn{7}{|c|}{$\begin{array}{l}\text { LVDD, left ventricular diastolic diameter; LVEF, left ventricular ejection fraction; MR, mitral regurgitation; } \\
\text { MS, mitral stenosis; MV, mitral valve; NYHA, New York Heart Association; post-TTE, postoperative } \\
\text { transthoracic echocardiography; pre-TEE, preoperative transthoracic echocardiography; pre-TTE, } \\
\text { preoperative transthoracic echocardiography; RVD, right ventricular diameter; sPAP, systolic pulmonary } \\
\text { artery pressure; SD, standard deviation; TAPSE, tricuspid annular plane systolic excursion }\end{array}$} \\
\hline
\end{tabular}

Table 3: Intraoperative and postoperative mean pressure gradients and functional areas categorized according to the type of surgery 


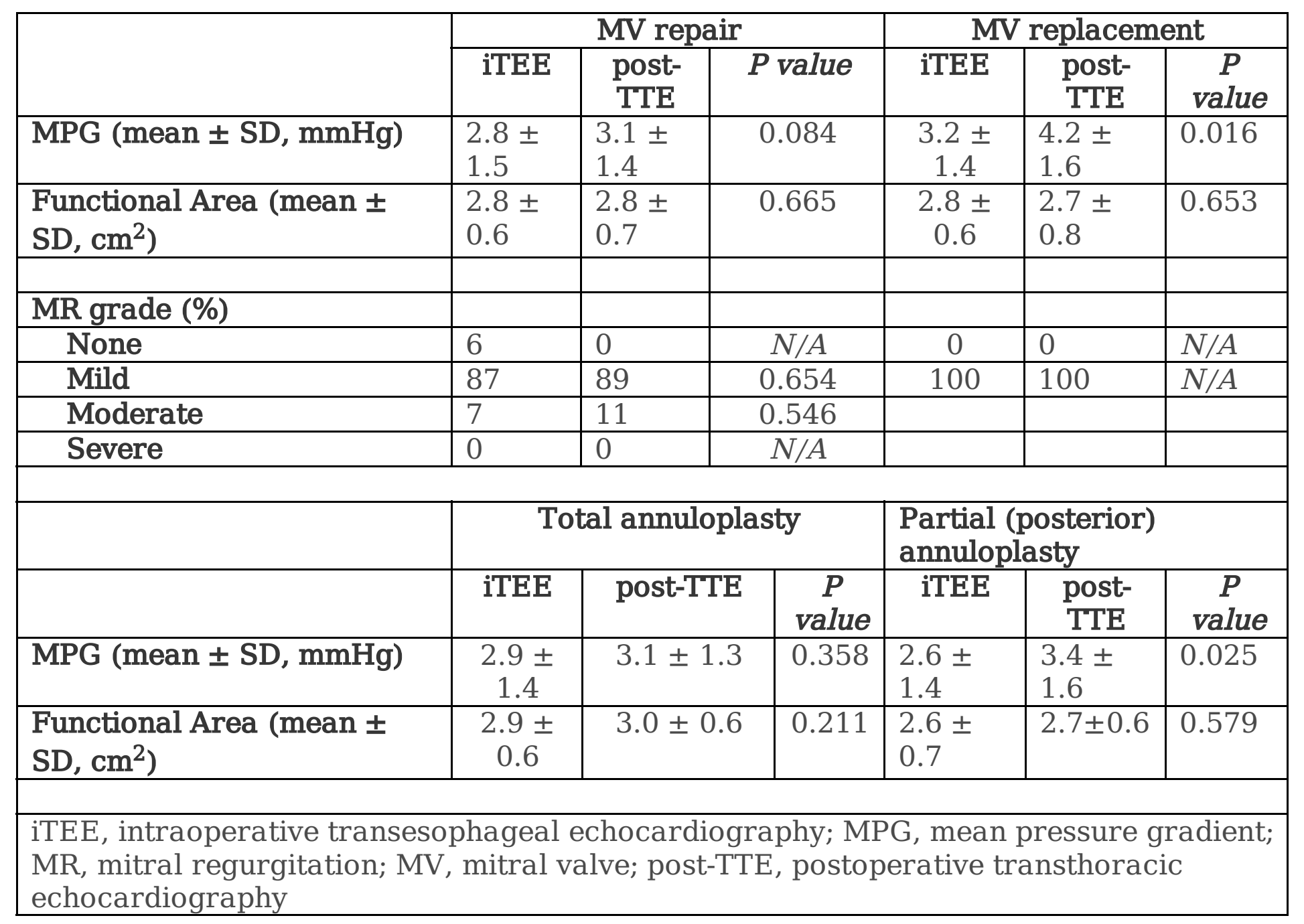

\section{Figures}



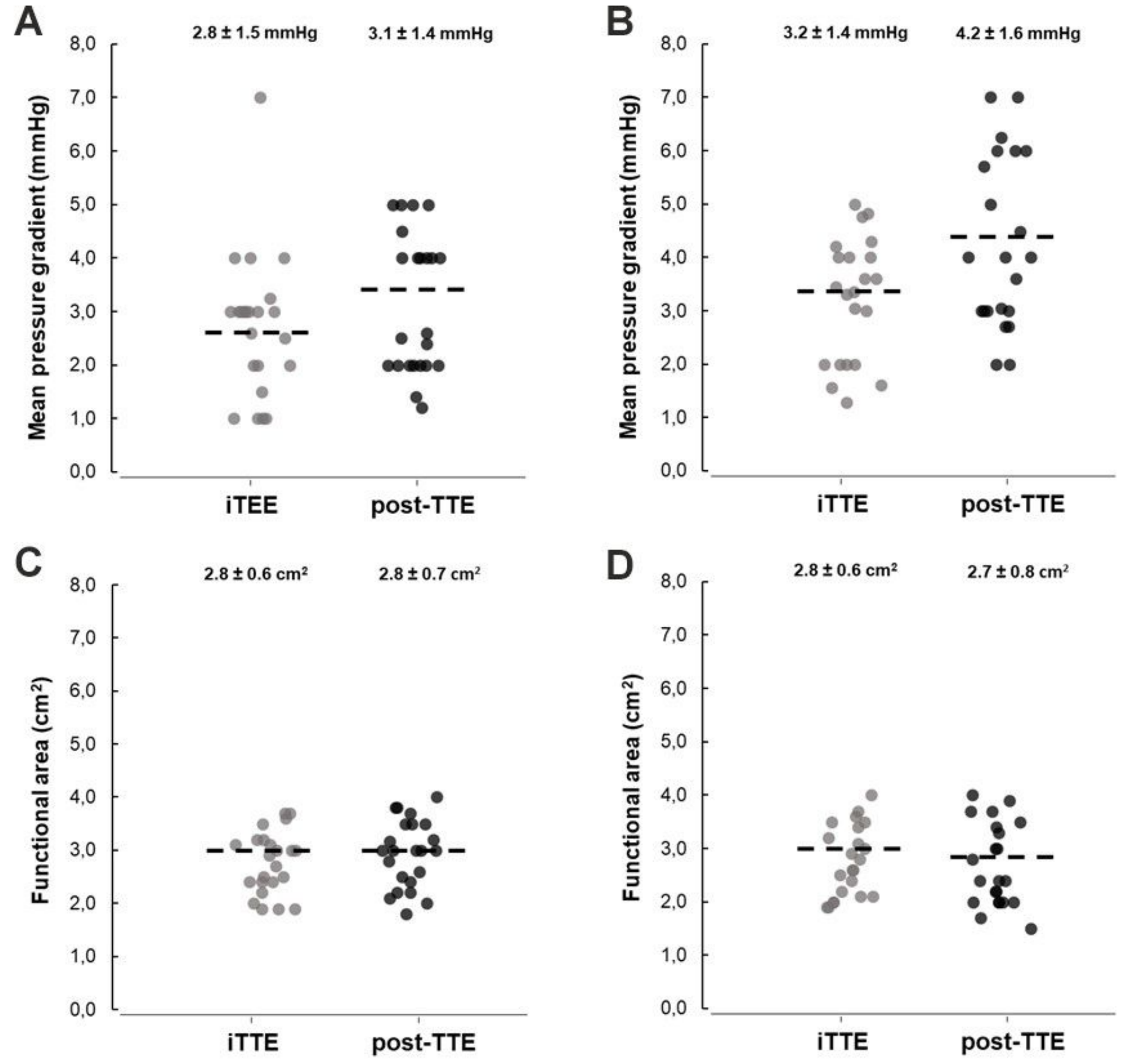

Figure 1

These graphs show the iTEE and post-TTE mean pressure gradients of MV repair patients $(A)$ and MV replacement patients (B), and the iTEE and post-TTE estimated functional mitral areas of MV repair patients (C) and MV replacement patients (D). The estimated functional mitral areas were calculated using the pressure half-time method. iTEE, intraoperative transesophageal echocardiography; MV, mitral valve; post-TTE, postoperative transthoracic echocardiography 